\title{
Contaminated sites, waste management, and green chemistry: new challenges from monitoring to remediation
}

\author{
Pablo L. Higueras ${ }^{1} \cdot$ Francisco J. Sáez-Martínez $^{1,2}\left(\mathbb{D} \cdot\right.$ Gilles Lefebvre $^{3} \cdot$ Régis Moilleron $^{3}$ \\ Received: 2 October 2018 / Accepted: 22 October 2018 / Published online: 9 November 2018 \\ (C) Springer-Verlag GmbH Germany, part of Springer Nature 2018
}

Human activities suppose a risk of generating contamination of the environment: all of these activities imply the modification of the media, including the landscape, and frequently also the quality of soil, water, and atmosphere in the surroundings. When these affections go further than certain thresholds, we have a contaminated site. Besides, the human activities also imply frequently the accumulation of wastes; even in the simplest way of life, inhabiting caves, the enlargement of the cave for new born humans generates the need of excavation to create a void, extracting materials that need to be accumulated more or less near the cave entrance, generating a residual heap. Nowadays, the management of contaminated sites and of wastes, many of them created or accumulated during many decades, or even centuries, represents an important need, since their extension has not stopped growing, in particular, from the development of the "Industrial Age." However, the task is not easy (nor cheap) to carry out, due to both the diverse nature of the "contaminants" distributed in the environment and to the extension of sites affected by this type of problem. Green chemistry is one of the tools developed to try to get solutions to this type of problems, in many different ways, including the development of chemical process able to mitigate the negative effects that certain contaminants may exert on the soil quality, or in the health of biota affected by such contaminants.

But, how can we identify properly "contaminated sites"? And how can we identify real risks related with the presence of contaminants or of wastes in the proximity of our industrial

Responsible editor: Philippe Garrigues

Francisco J. Sáez-Martínez

francisco.saez@uclm.es

1 University of Castilla-La Mancha, Ciudad Real, Spain

2 Faculty of Economics, Plaza de la Universidad, 1, 02071 Albacete, Spain

3 University of Paris-Est Créteil, Créteil, France sites (or sometimes in urban areas)? Of course, the basis of this is the needed baseline information, meaning what should be the "normal" characteristics of an area considered as not contaminated. This information is not so easy to get; some maps register diverse parameters on the quality of different environmental parameters. As an example, geochemical maps of entire continents, of entire countries, or entire regions are available in commercial basis and/or in the scientific literature. But not all parameters of interest in this sense are always registered on such maps. Even the ones that should be more useful, as the contents in metals which are considered as potentially toxic, may not be appropriate, since maps usually register total contents in those elements and not the portions of those elements susceptible of being incorporated into other environmental compartments: which fraction of the total content is water soluble and so is available for migration from soil to aquatic systems?; which fraction can be uptake by plants? In each case, therefore, it is a real need to identify the regional baseline parameters which may serve as a local reference to identify the areas that should be identified as contaminated, in which the analytical of air, water, or soil quality suppose the real risk of affecting the health of humans, directly or indirectly (by means of direct or indirect transference to the food chain).

The present special issue (SI) of Environmental Science and Technology presents a number of studies dealing with some of these aspects, which were presented as scientific contributions to the "Third Energy and Environment Knowledge Week" (E2KW), held in Paris (France) on 28-29 October 2016. Drawing from selected contributions to this international congress, the SI gathers novel and timely research on contaminated sites, waste management, and green chemistry. A group of papers is focused on environmental quality monitoring. Three additional papers present green chemistry alternatives to mitigate contamination effects and to obtain useful products from agricultural wastes. Finally, two papers are focused on modeling environmental and related processes. The first one aims to improve the estimations of $\mathrm{CO}_{2}$ 
emissions worldwide, and the second one aims to improve the environmental management of hospitals and other health care organizations.

\section{Environmental quality monitoring}

The delimitation of contaminated areas is performed by the characterization of baselines and anomalies, usually by means of analytical methods; statistics is a useful tool to set thresholds separating "normal" values from "anomalous" values that can characterize a contaminated site or area. Besides, the term "anomaly" has been used by ore mineral prospectors and something of natural origin: the anomaly should be an indication of the natural presence of ore minerals, what is particularly interesting if there were no previous indications of the existence of such ore minerals in the area under mining research. However, sometimes the mines researcher finds that the supposed "new" anomaly is not that "new," and discovers that the "anomaly" is a consequence of some human activity formerly active in the area. These humans-produced "anomalies" are then called contamination. In any case, both "natural" and "human-produced" anomalies may suppose, in certain conditions, risks for the environment, for biota, and for humans, and then also suppose a need of a risk assessment, and in some cases, of actuations aimed to minimize the unveiled risks. Bravo et al. (2018) present geochemical data obtained from agricultural soils from Castilla-La Mancha region (South Central Spain) aimed to identify the "reference values" or thresholds needed to separate the baseline from the anomalous values in a wide area. They use an analytical method which can be considered as promising for this kind of studies: X-ray fluorescence spectrometry, a technique providing rapid and cheap information concerning the total elemental contents of a nice number of elements with exactitude and precision enough to let a statistical analysis and a study of the geographic distributions of the regional background levels, and of the areas with potential to be classified as contaminated. Garcia-Ordiales et al. (2018) refer to another environmental compartment which are sediments accumulated during historic times in coastal areas, and to their capacity to register accumulations of potentially toxic elements ( $\mathrm{As}, \mathrm{Sb}$ and $\mathrm{Hg}$ ) released in a wide area by diverse mining activities, in particular, in the well-known mining areas of Central Asturias, in North Spain. Their detailed analysis of data registered in these sediments, including their precise dating, makes evident that the human activities developed in the area since the beginning of twentieth century have supposed an important increment of the presence of those pollutants in the regional environment; besides, and being the studied accumulations susceptible of erosive processes, they still represent a risk for the future of the area. The presence of mercury in Almadén (Castilla-La Mancha region of Spain) is well known, and the environmental consequences of this fact have been described in a large number of publications; however, Barquero et al. (2018) present a novel methodology to quantify the atmospheric contamination related with the fact that this element has a high volatilization potential, being present in the atmosphere of areas in which there is no active sources of direct release of the element to the atmosphere, which is the case for this area after the cessation of mining and metallurgy and the reclamation of the mine's main dump (Tejero et al. 2015). In particular, these authors use the bioaccumulation capacity of needles of stone pine to biomonitor the mercury presence in the atmosphere. Besides, the authors discuss the possibility of soil precedence of mercury accumulated in the needles, finding no evidences of this possibility. Mercury concerns are also the subject of the research work presented by Lominchar et al. (2018), referring to the bioaccumulation of mercury species, and in particular, of its most toxic one, methylmercury, in the tissues of the macrophyte plant species Typha domingensis living in the riverbanks of the fluviatile systems of the Almadén mercury mining district. The paper applies to plant tissues a recent analytical procedure specifically developed for aquatic plants by Jiménez-Moreno et al. (2018) and based on nitric extraction in a microwave system, and with simultaneous determination of $\mathrm{Hg}$ species by derivatization with sodium tetraethylborate and injection into gas chromatography-pyro-atomic fluorescence spectrometry. The obtained results validate the applicability of this technique to plant tissues and show how mercury species tend to be accumulated in the belowground fractions with a low translocation rate to the aerial part.

\section{Green chemistry-based developments}

Green chemistry, also called sustainable chemistry, is an area of chemistry and chemical engineering focused on the design of products and processes that minimize the use and generation of hazardous substances (USEPA 2006). This discipline of chemistry is, therefore, aimed to develop and validate new technologies and protocols to reduce environmental risks related with contamination and wastes disposal. These are also the aims of three contributions included in this special issue. Ionic liquids are complex compounds, developed in the context of green chemistry aimed to replace organic compounds as 
"green-solvents." However, different studies have demonstrated their toxicity in different environmental compartments (soils, water, and sediments) (Frade and Afonso 2010, among others), what supposes the need of novel technologies for their removal from aquatic environment. Meijide et al. (2018) assess the application of an electro-Fenton process for the degradation of one of these ionic liquids, developing a procedure which reveals a notable detoxification, and can be generalized to the demonstration of the high catalyst ability of some of these compounds by the proposed methodology.

Chromium, and in particular hexavalent ions of this element, is well-known toxicants of natural systems, producing even carcinogen effects on human populations exposed to this ions, mainly through drinking water (Costa 2003, among others). Aranda-García and Cristiani-Urbina (2018) present a kinetic study concerning the usage of avocado fruits shell for the removal of total and hexavalent $\mathrm{Cr}$ from aqueous solutions. They implement $\mathrm{pH}$-shift batch, $\mathrm{pH}$-controlled batch, and continuous packed bed column systems, verifying the importance of the $\mathrm{pH}$ in the redox reactions involved in the biotransformation of hexavalent $\mathrm{Cr}$ to trivalent $\mathrm{Cr}$. Furthermore, their results indicate that avocado shell is capable of removing hexavalent $\mathrm{Cr}$ from the aqueous solution by means of a mixed mechanism involving the bioreduction of the highly toxic ion to the much less toxic ion trivalent $\mathrm{Cr}$ and the biosorption of this.

The green chemistry can also be used to produce chemical precursors from food wastes as alternatives to petroleum derivatives. Among these wastes, the wine industry produces an important volume of grape seeds that are mainly use as biofuel for energy production, attending to the low gastronomic and economic interest (Fiori et al. 2012). In that way, by using the green chemistry, it is possible to transform this waste in an important product having a high added value. A large amount of grape seed oil can be extracted from the seeds, and further, the double bonds present in the oil can be chemically transformed into epoxy or hydroxyl groups. The contribution from de Haro et al. (2018) corresponds to an experimental work aimed to obtain a rigid polyurethane foam based on the chemical processing of those winery wastes. The final material presented improved flame-retardant properties so it was also suitable to be implemented as insulation in building. Their results confirm the possibility of using the phosphorylated biopoliols obtained from the grape seed oils as an important substitute of the petroleum-based polyester polyols. Hence, this article indicates that it is possible to produce materials having specific properties for further application by using the green chemistry and also reducing the negative impact on the green house and global warming than that from the petroleum-based presents.

\section{Modeling environmental and related processes}

Models are approximations to real conditions based on real observations and aimed to make approach to theoretical different conditions. This special issue includes two modelsbased studies, with different objectives: Navarro et al. (2018) present a model of human population dynamics to be used to improve the estimations of $\mathrm{CO}_{2}$ emissions. The model, suitable for being embedder into Earth System Models, simulates historical population dynamics with a high special resolution; the results are used to make realistic estimation on quantification of spatial distribution of $\mathrm{CO}_{2}$ emissions. The model was compared with other emissions inventories and properly validated, and therefore, it can be used to improve the overall quality of the Earth System Models.

Health care organizations, including hospitals as main subjects, can be considered as important sources of environmentrelated concerns, including energy consumption, atmospheric emissions, generation of hazardous waste, management of suppliers, environmental sensitivity of staff, etc. (Carnero 2015). However, no previous assessments of the possibilities to improve their management in these aspects have been published. Romero and Carnero (2018) take into account all these factors to design a multi-criteria model for environmental assessment of these entities. The model is based on a multi-criteria analytical hierarchy process and has been applied to a real case, corresponding to a Spanish hospital in order to validate the results.

The papers presented in this SI show cutting edge research on environmental quality monitoring and how green chemistry can be used to mitigate contamination effects and to obtain useful products from waste. Authors and reviewers are greatly acknowledged for their contributions as well as Dr. Philippe Garrigues ESPR Editor-in-Chief for his help and support during the preparation of this special issue. For additional information about the E2KW 2016 conference speakers and titles, please see http://congresse $2 \mathrm{kw}$.uclm.es. This conference was organized by the Energy and Environment Science and Technology Campus of International Excellence-CYTEMAof the University of Castilla-La Mancha and University of Paris-Est Créteil.

\section{References}

Aranda-García E, Cristiani-Urbina E (2018) Effect of pH on hexavalent and total chromium removal from aqueous solutions by avocado shell using batch and continuous systems. Environ Sci Pollut Res Int. https://doi.org/10.1007/s11356-017-0248-z

Barquero JI, Rojas S, Esbrí JM, García-Noguero EM, Higueras P (2018) Factors influencing mercury uptake by leaves of stone pine (Pinus pinea L.) in Almadén (Central Spain). Environ Sci Pollut Res Int. https://doi.org/10.1007/s11356-017-0446-8 
Bravo S, García-Ordiales E, García-Navarro FJ, Amorós JA, Pérez-de-losReyes C, Jiménez-Ballesta R, Esbrí JM, García-Noguero EM, Higueras $P$ (2018) Geochemical distribution of major and trace elements in agricultural soils of Castilla-La Mancha (Central Spain). Finding criteria for baselines and delimiting regional anomalies. Environ Sci Pollut Res Int. https://doi.org/10.1007/s11356-017-0010-6

Carnero MC (2015) Assessment of environmental sustainability in health care organizations. Sustainability 7(7):8270-8291

Costa M (2003) Potential hazards of hexavalent chromium in our drinking water. Toxicol Appl Pharmacol 188:1-5

Fiori L, Valbusa M, Lorenzi D, Fambri L (2012) Modeling of the devolatilization kinetics during pyrolysis of grape residues. Bioresour Technol 103:389-397

Frade RFM, Afonso CAM (2010) Impact of ionic liquids in environment and humans: an overview. Hum Exp Toxicol 29:1038-1054

Garcia-Ordiales E, Cienfuegos P, Roqueñí N, Covelli S, Flor-Blanco G, Fontolan G, Loredo J (2018) Historical accumulation of potentially toxic trace elements resulting from mining activities in estuarine salt marshes sediments of the Asturias coastline (northern Spain). Environ Sci Pollut Res Int. https://doi.org/10.1007/s11356-017-0449-5

de Haro JC, López-Pedrajas D, Pérez A, Rodríguez JF, Carmona M (2018) Synthesis of rigid polyurethane foams from phosphorylated biopolyols. Environ Sci Pollut Res Int. https://doi.org/10.1007/ s11356-017-9765-z

Jiménez-Moreno M, Lominchar MA, Sierra MJ, Millán R, MartínDoimeadios RCR (2018) Fast method for the simultaneous determination of monomethylmercury and inorganic mercury in rice and aquatic plants. Talanta 176:102-107

Lominchar MA, Sierra MJ, Jiménez-Moreno M, Guirado M, Rodríguez Martín-Doimeadios RC, Millán R (2018) Mercury species accumulation and distribution in Typha domingensis under real field conditions (Almadén, Spain). Environ Sci Pollut Res Int. https://doi.org/ 10.1007/s11356-018-1861-1

Meijide J, Pazos M, Sanromán MA (2018) Heterogeneous electro-Fenton catalyst for 1-butylpyridinium chloride degradation. Environ Sci Pollut Res Int. https://doi.org/10.1007/s11356-017-0403-6

Navarro A, Moreno R, Jiménez-Alcázar A, Tapiador FJ (2018) Coupling population dynamics with earth system models: the POPEM model. Environ Sci Pollut Res Int. https://doi.org/10.1007/s11356-017$0127-7$

Romero I, Carnero MC (2018) Environmental assessment in health care organizations. Environ Sci Pollut Res Int. https://doi.org/10.1007/ s11356-017-1016-9

Tejero J, Higueras P, Esbrí JM, Garrido I, Oyarzun R, Español S (2015) An estimation of mercury concentrations in the local atmosphere of Almadén (Ciudad Real Province, South-Central Spain) during the 20th century. Environ Sci Pollut Res 22:4833-4841

USEPA (2006) "Green Chem". United States Environmental Protection Agency. 2006-06-28. https://www.epa.gov/greenchemistry. Retrieved May 3, 2018

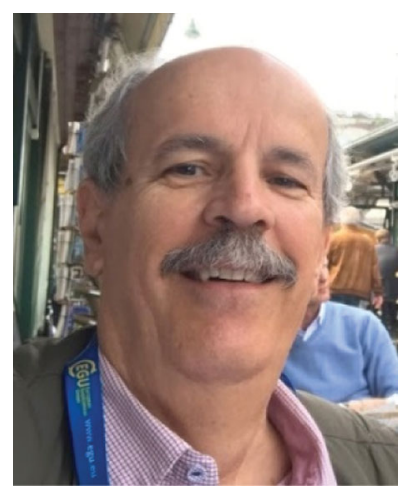

Pablo L. Higueras is a full professor of mining research at "Escuela de Minas de Almadén," University of Castilla-La Mancha (UCLM), Spain. He is also the director of the "Instituto de Geología de Geología Aplicada" (IGeA-UCLM). He graduated in Earth Sciences at University of Granada, Spain (UGr). He worked as junior and senior geologist at two Spanish mining companies (1980-1990), and in 1990, he started his research and teaching career at UCLM and got his $\mathrm{PhD}$ also from UGr. His research interest has been focused on environmental problems associated with mining activity, with environmental (bio)geochemistry of potentially toxic elements (particularly mercury) as main target. He has authored more than 150 publications, 80 of them in SCI journals, and has presented more than 200 communications in national and international conferences. His continuous cooperation with Iberoamerican research institutions is also noteworthy.

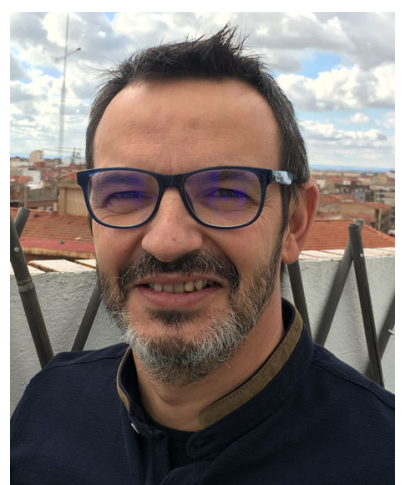

Francisco José Sáez-Martínez is a Professor of Management at the Faculty of Economics, University of Castilla-La Mancha (UCLM), Spain. He received a degree in economics and business administration from the University of Valencia and a $\mathrm{PhD}$ in management from the University of Castilla-La Mancha. He has been the coordinator of the Energy and Environment Science and Technology Campus of International Excellence (CYTEMA) since July 2012. He is a member of the technical and consulting scientific committee of the Spanish National Hydrogen Center (CNH2). He has been a visiting researcher at Purdue University (USA), University of Florence (Italy), and Dublin City University (Ireland) and a visiting lecturer at the Universidad del Pacífico (Peru), Universidad Andina Simón Bolívar (Bolivia), and Universidad Autónoma Gabriel René Moreno (Bolivia). His recent research interest is focused on corporate entrepreneurship and ecoinnovation and has been published in international journals such as the Journal of Business Ethics, the Journal of Knowledge Management, and the Journal of Cleaner Production, among others. 


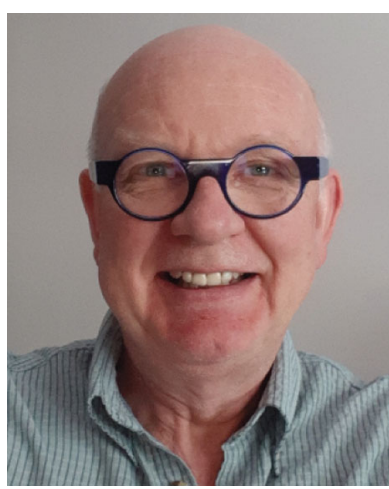

Gilles Lefebvre is a Professor in Thermodynamic, Heat Transfer, Renewable Energies and Energy Efficiency at University Paris East in Créteil (UPEC) and vice director of the Center for Research and Development in Heat Transfer, Environment and Systems (CERTES). He obtained his $\mathrm{PhD}$ thesis of Univesity Pierre and Marie Curie (UPMC) in École des Mines ParisTech in 1987, then joined the École des Ponts-ParisTech where he headed a building modeling research center. Since 2000, he is a professor at UPEC. He teaches at UPEC and Universities Paris East at Marne la Vallée, Paris South in Orsay. He is an associated professor at the National University of Engineering in Lima (Peru) where he teaches and supervises research works at Bachelor, Master, and $\mathrm{PhD}$ level. He developed and manages a professional Bachelor formation in Renewable and Efficient Energies of Sustainable Buildings at UPEC (EREEBAT).

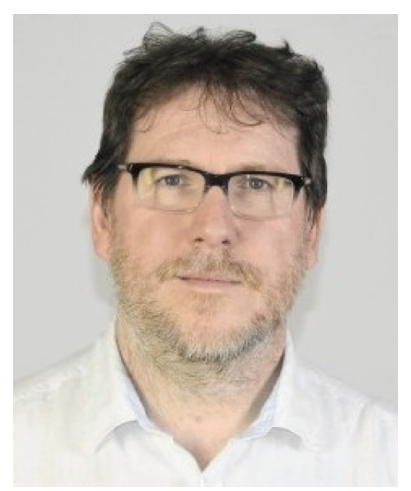

Régis Moilleron is a full professor of Environmental Chemistry at Laboratory of Water, Environment and Urban Systems (Leesu), a joined research unit from University of Paris-Est Créteil, École des Ponts ParisTech, and AgroParisTech (France). He has a Ph.D. in Physical Chemistry from the University of Franche-Comté, France. He moved from applied research in urban hydrology and analytical chemistry to management position, and he is running his research unit since 2014. His research interests are mainly focused on the fate of emerging contaminant and their spatial variability in urban environment in connection to uses of daily life products. Recently, he developed researches on the fate of personal care products (parabens and triclosan in the Cosmet'eau project) and biocides (thiazolinones, diuron, etc. within the framework of the OPUR observatory). He authored more than 80 scientific and he has supervised $16 \mathrm{PhDs}$ in Environmental Science since 2000. 